\title{
Milk choices made by women: what influences them, and does it impact on calcium intake?
}

\author{
KM Cashel ${ }^{1, *}$, D Crawford $^{2}$ and V Deakin ${ }^{1}$ \\ ${ }^{1}$ Gadi Research Centre, University of Canberra, ACT 2601, Australia : ${ }^{2}$ School of Health Sciences, Deakin \\ University, Victoria 3125, Australia 3127
}

Submitted 22 November 1999: Accepted 20 March 2000

\begin{abstract}
Objective: To identify influences on type of milk consumed and the impact of milk choice on calcium intakes in Australian women of pre- and postmenopausal age. Design and setting: Questionnaires covering calcium intake, health-related dietary issues and priorities self-completed in a group setting.

Subjects: A total of 300 women recruited from community groups and government departments.

Results: Mean milk and calcium intake were higher in older ( $\geqslant 50$ years) compared to younger women. Milk provided over 50\% of calcium intake for both groups. Participants rated the importance of eating foods low in fat, energy or cholesterol, high in calcium or dietary fibre or of limiting their intake of added sugar or sugary foods'. Younger and older women ranked eating foods low in fat as the most important food habit for their health, then ranked dietary fibre next in importance. Calcium ranked third for younger women, and fourth for older women. These rankings were reflected in the higher proportion of older women choosing fatreduced milk in general, and skim milk in particular. This concern about eating foods low in fat was consistent with the choices made of skim, reduced fat/higher calcium or whole milk.

Conclusions: Results from this study suggest that concerns about fat are prejudicing the type of milk and amount of calcium consumed. Public health strategies targeting calcium intake need to address age-related differences in quantity and type of milk consumed, including the food attribute conflicts influencing these.
\end{abstract}

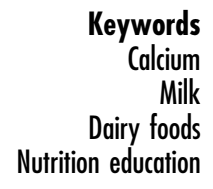

Recent concern about calcium intakes by women and adolescent girls led to the recommendation to 'eat foods containing calcium' being added to the Australian dietary guidelines for adults ${ }^{1}$, children and adolescents ${ }^{2}$. The recommended dietary intake (RDI) levels of calcium for adolescent and postmenopausal women were also raised $^{3,4}$. These changes to public health nutrition references and policy not only reflected the increasing prevalence and health care costs of osteoporosis, but the evidence for the importance of calcium intake in optimizing bone mass in the first two to three decades of life in relation to lifelong bone density ${ }^{5-7}$, the potential benefits of optimal calcium intake on minimizing bone loss in postmenopausal women ${ }^{5-7}$, and reported suboptimal calcium intakes in these at-risk groups ${ }^{8,9}$. National dietary surveys of urban adults ${ }^{9}$ and of school children aged 10-15 years ${ }^{8}$ suggested that, on any particular day, considerable proportions of girls (24-30\%) and postmenopausal-aged women (36\%) were consuming less than $50 \%$ of the RDI for calcium. For boys and men, the proportions were lower (11-29\% and 16\%, respectively).
While comparisons are not available from the 1995 National Nutrition Survey (NNS), it was reported that, regardless of age category, 'generally less than 50\% of females had a calcium intake that exceeded the RDI ${ }^{10}$. By itself, these findings are not evidence of a deficiency of this nutrient in the community. However, the current predictions for increasing prevalence and health costs of osteoporosis in postmenopausal women suggests the desirability of proactive measures to increase calcium intakes in the Australian population ${ }^{11,12}$.

Food supply data demonstrate that the most important source of calcium in Australia is milk and milk products ( $75 \%$ of total), and within this group of foods, milk (fresh, dried or canned) contributes $69 \%$ of all calcium available for consumption ${ }^{13}$. The evidence from national dietary surveys is consistent with this ${ }^{8-10}$. Dietary survey data in the mid-1980s suggested that, for adolescent girls, the increase in the consumption of milk and its products with age was less than that needed for growth ${ }^{14}$, and that consumption decreased with age in the case of adult women $^{15}$. In both surveys, those age groups with the 
highest requirement for calcium reported the lowest intakes of milk products relative to recommended intakes. However, surveys of adults in the states of Victoria (1985 and 1990) and South Australia (1988 and 1993) suggested that calcium intakes of women have increased over more recent times, particularly for older women. This is despite the fact that consumption of milk and its products did not necessarily increase ${ }^{16,17}$. This apparent anomaly was due in part to an increase in consumption of other foods that contribute to calcium intake (e.g. processed meats), but mostly reflects the introduction of higher calcium milks. In contrast, data from the 1995 NNS suggest that there has been a decrease in milk consumption but increases in consumption of other milk products by adolescent girls, but, for older women, an increased consumption of milk and yoghurt and a decrease in cheese consumption ${ }^{18}$. This, and other changes in the diet, results in a very modest increase in calcium consumption by both adolescent girls and adult women ${ }^{10}$ since the 1983 and 1985 Australian surveys ${ }^{8,9}$. This is consistent with the small increase reported in the calcium available per capita in the food supply over this time ${ }^{13,19}$.

The increasing public awareness and concern about fat intake $^{20-25}$, particularly animal fat intake, has seen the production and promotion of a range of lower fat milks in Australia. While skim milk has been available for some time, it is not commonly consumed. The more recently introduced reduced fat milks (e.g. $50 \%$ reduction in fat content) have been more successful with consumers, as have low-fat calcium-increased milks. In recent years, there has been strong generic promotion of the consumption of milk and milk products to the population in general and to women and children in particular. This has been accompanied by specific brand promotion of reduced fat milks. Through the addition of skim milk powder, these products have improved taste acceptance as well as higher calcium levels than the generic whole and skim milks. While the quantity of these products consumed by the overall Australian community is well documented $^{26,27}$, little is known about the quantities of the various types of milk being consumed by subgroups in the population, and more importantly, what is influencing these choices. Further, there are few reports specifying the impact of choice of milk type on calcium intake.

The aim of this study was to examine the calcium intakes and their food sources of two groups of women (those under 50 years and those aged 50 years and over). In particular, the quantity and type of milk consumed was examined and the sociodemographic, health and dietary influences on type of milk consumed were assessed. Information such as this will assist in better targeting of health messages to pre- and postmenopausal women by demonstrating the impact of milk choices on calcium intakes.

\section{Methods}

\section{Subjects}

Three hundred women were recruited to the study and data were collected in August 1995. The sampling, while opportunistic, aimed to capture data from equally sized groups of women who were pre- and post- the median age of menopause ( 50 years) ${ }^{28,29}$. The majority of older women ( $\geqslant 50$ years) were recruited through community groups, with most of the younger women $(<50$ years) recruited from randomly selected federal and Australian Capital Territory (ACT) government departments. The sample comprised eight women's groups and nine departments in the ACT or federal public service. The number of subjects in groups varied from seven to 22 for the women's groups and from 10 to 50 for the federal and ACT government departments. Approval for this project was granted by the University of Canberra's Human Experimentation and Ethics Committee. Participants were provided with written background information about the study and provided written consent prior to data collection.

\section{Measures}

A questionnaire to obtain background information, usual calcium intake and related beliefs, attitudes and behaviours, as well as relevant health information was developed. The questionnaire was pilot tested on a subsample of women prior to data collection to check suitability and design. In the main study, questionnaires were completed by small groups, in the work environment or in community settings. Subjects were instructed verbally using a standard protocol. Around 5\% of older subjects needed assistance to complete the survey either as a result of visual impairment or arthritis.

\section{Background information}

Questions were included that sought information about highest level of education, current employment situation and living arrangements, weight, height, perception of current health and known health problems.

\section{Calcium intake}

A 34-item semiquantitative food frequency questionnaire (FFQ) previously developed and validated for Australian women aged 29-74 years was used to measure calcium intake. This instrument, its development and validation against a 4-day record after intervals of 1 week (26 women) and 12 months ( 28 women) has been previously published $^{30}$. Subjects recalled commonly consumed foods containing calcium and the quantity usually consumed on a daily or weekly basis in standard household, metric or imperial measures. The original questionnaire asked about usual type of milk drunk, total amount of milk usually consumed per day (selection from specified volumes ranging from ' 1.5 pints or 1 litre' to 'no milk'), number of cups of tea/coffee with milk per day, amount of milk with 
breakfast cereal and the number of slices of bread eaten each day. For the rest of the foods listed in the FFQ, the amount eaten each week was sought. For open-ended questions, an example of volume per household measure was given (e.g. $0.5 \mathrm{cup}=125 \mathrm{ml}$ ). In the modified version, the usual type of milk drunk each day was combined with how much was consumed each day (open-ended) as well as the rest of the questions relating specifically to milk. In addition, participants were asked if they used milk or ate bread daily. If their response was 'no', they were asked how much they consumed in a week. Information regarding type and frequency of use of calcium or multinutrient supplements was also collected.

\section{Factors influencing milk intake}

Subjects were asked to rate the importance of eating foods which were: 'low in fat'; 'high in fibre'; 'high in calcium'; 'low in cholesterol'; 'low in calories/kilojoules'; or of 'limiting your intake of added sugars and sugary foods' using a five point Likert scale ('very high', 'high', 'low', 'very low' or 'not sure'). Finally, subjects were asked to rank these dietary components as 'most' to 'third most important' to their health.

\section{Data analysis}

The participants in the survey were divided into two groups, those aged less than 50 years (younger women) and those aged 50 years and older (older women). This division was based on the median age of menopause in western women ${ }^{28,29}$. Calcium intake was calculated using data from the Composition of Foods, Australia series ${ }^{31-33}$. Calcium from supplements was not added to the dietary intake data. Milks were categorized as 'whole milks' (3.9\% fat and $120 \mathrm{mg} \mathrm{Ca} 100 \mathrm{ml}^{-1}$ ), reduced fat/higher calcium (1.4-2\% fat, $\left.140 \mathrm{mg} \mathrm{Ca} 100 \mathrm{ml}^{-1}\right)$, high calcium/skim

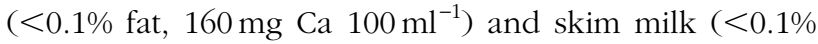
fat, $120 \mathrm{mg} \mathrm{Ca} 100 \mathrm{ml}^{-1}$ ). Non-milk consumers (13 women) were excluded from analyses specific to milk consumers per se. Women who consumed more than one type of milk (eight women) were excluded from those analyses that used type of milk consumed as a variable.

All data were analysed using SPSS version 8. Categorical data were tested for differences using chi-square analyses. Continuous data (i.e. quantity of milk consumed, calcium intake) were subjected to logarithmic transformation to ensure homogeneity of variance prior to analysis of variance testing where applicable. All data in tables for means and variance are reported as non-adjusted data. An $\alpha$ level of $P<0.05$ was adopted for statistical comparisons.

\section{Results}

\section{Profile of participants}

The mean age of all participants was 52 years (19 SD), ranging from 23 to 91 years. The mean age of the younger aged and older aged groups was 37 years (6 SD) and 69 years (12 SD), respectively. The older women had a higher mean body mass index (BMI) than the younger women ( 23.6 vs. $25.4 \mathrm{~kg} \mathrm{~m}^{-2}$ ). The two groups were significantly different in level of education, employment profile and living arrangements. Forty-six per cent of younger women had university qualifications compared with $14 \%$ of the older women. Most of the younger women were in the work force (70\% full time, $20 \%$ part time) and a smaller proportion of older women were in the work force $(21 \%$ full time, 3\% part time). Sixty-two per cent of older women were retired; $48 \%$ of older women lived alone, and $39 \%$ lived in adult-only households. Thirty-six per cent of younger women lived in adult-only situations, but half lived in households that included children.

\section{Calcium intake and major sources}

\section{All participants}

The mean calcium intake for all women was $743 \pm$ $436 \mathrm{mg} \mathrm{day}^{-1}$, with no significant differences between the mean calcium intakes of the older women (792 \pm $\left.464 \mathrm{mg} \mathrm{day}^{-1}\right)$ and younger women $\left(698 \pm 405 \mathrm{mg} \mathrm{day}^{-1}\right)$. For both groups, milk and milk products were the major contributors of calcium, contributing $86 \%$ of the total calcium. The contribution from non-milk-based foods was very similar between the two groups, at around $100 \mathrm{mg} \mathrm{day}^{-1}$. Mean daily milk consumption was greater for older women $(388 \pm 304 \mathrm{ml})$ than younger women $(301 \pm 240 \mathrm{ml})(P=0.044)$. Milk was the predominant source of calcium for both groups of women, contributing $56 \%(393 \pm 308 \mathrm{mg})$ of the calcium in the younger women's diets and $66 \%(454 \pm 370 \mathrm{mg})$ of the older women's diets $(P=0.019)$. For younger women, milk products (i.e. yoghurts, cheeses and ice-cream) contributed more calcium $(209 \pm 169 \mathrm{mg})$ than for older women $(169 \pm 151 \mathrm{mg}$ ) (30\% vs. $21 \% ; P=0.036)$. Higher consumption of hard cheeses by younger women was the reason for this difference $(P=0.018)$. Cheeses (soft and hard) contributed $67 \%$ of the calcium from milk products in the younger women $(139 \mathrm{mg}$ ) compared with $62 \%$ for the older women $(105 \mathrm{mg})$.

\section{Milk consumers}

Of the 298 women who completed the FFQ, nine younger and four older women reported consuming no milk in the previous week. These subjects were excluded from analyses specific to milk consumers per se. Eight subjects (five younger and three older women) split their consumption between two milk types, usually a combination of whole milk and a skim or reduced fat milk. The younger and older women differed in the types of milk chosen and the quantity of milk consumed. Over half of the younger women (57\% of 143 milk consumers) consumed whole milk, $24 \%$ consumed reduced fat/ higher calcium milk, and similar numbers chose the high calcium/skim milk (12\%) and skim milk (10\%). The older 
Table 1 Relative importance to milk consumers* of eating foods low in fat, cholesterol or energy, or high in calcium or dietary fibre (per cent respondents)

\begin{tabular}{|c|c|c|c|c|c|c|c|}
\hline & $n$ & $\begin{array}{c}\text { Not } \\
\text { important } \\
(\%)\end{array}$ & $\begin{array}{l}\text { Not } \\
\text { sure } \\
(\%)\end{array}$ & $\begin{array}{c}\text { Quite } \\
\text { important } \\
(\%)\end{array}$ & $\begin{array}{c}\text { Very } \\
\text { important } \\
(\%)\end{array}$ & $\begin{array}{c}\text { Extremely } \\
\text { important } \\
(\%)\end{array}$ & $P \dagger$ \\
\hline $\begin{array}{l}\text { Low in fat } \\
\text { Younger women } \\
\text { Older women }\end{array}$ & $\begin{array}{l}146 \\
127\end{array}$ & $\begin{array}{r}13.0 \\
6.3\end{array}$ & $\begin{array}{l}0.7 \\
2.4\end{array}$ & $\begin{array}{l}37.0 \\
24.4\end{array}$ & $\begin{array}{l}34.2 \\
37.8\end{array}$ & $\begin{array}{l}15.1 \\
29.1\end{array}$ & 0.006 \\
\hline $\begin{array}{l}\text { Low in cholesterol } \\
\text { Younger women } \\
\text { Older women }\end{array}$ & $\begin{array}{l}146 \\
123\end{array}$ & $\begin{array}{r}18.5 \\
5.7\end{array}$ & $\begin{array}{r}2.1 \\
13.0\end{array}$ & $\begin{array}{l}34.2 \\
22.8\end{array}$ & $\begin{array}{l}30.8 \\
35.8\end{array}$ & $\begin{array}{l}14.4 \\
22.8\end{array}$ & 0.000 \\
\hline $\begin{array}{l}\text { High in calcium } \\
\text { Younger women } \\
\text { Older women }\end{array}$ & $\begin{array}{l}146 \\
126\end{array}$ & $\begin{array}{l}6.2 \\
4.4\end{array}$ & $\begin{array}{l}1.4 \\
8.7\end{array}$ & $\begin{array}{l}41.8 \\
30.2\end{array}$ & $\begin{array}{l}37.7 \\
31.7\end{array}$ & $\begin{array}{l}13.0 \\
25.4\end{array}$ & 0.002 \\
\hline $\begin{array}{l}\text { Low in energy } \\
\text { Younger women } \\
\text { Older women }\end{array}$ & $\begin{array}{l}144 \\
123\end{array}$ & $\begin{array}{r}25.0 \\
8.9\end{array}$ & $\begin{array}{l}2.8 \\
7.3\end{array}$ & $\begin{array}{l}36.1 \\
30.9\end{array}$ & $\begin{array}{l}20.8 \\
37.4\end{array}$ & $\begin{array}{l}15.3 \\
15.4\end{array}$ & 0.001 \\
\hline $\begin{array}{l}\text { High in dietary fibre } \\
\text { Younger women } \\
\text { Older women }\end{array}$ & $\begin{array}{l}146 \\
125\end{array}$ & $\begin{array}{r}11.6 \\
1.6\end{array}$ & $\begin{array}{l}0.7 \\
4.8\end{array}$ & $\begin{array}{l}32.9 \\
29.6\end{array}$ & $\begin{array}{l}38.4 \\
40.8\end{array}$ & $\begin{array}{l}16.4 \\
23.2\end{array}$ & 0.003 \\
\hline $\begin{array}{l}\text { Limited in added sugars } \\
\text { Younger women } \\
\text { Older women }\end{array}$ & $\begin{array}{l}146 \\
129\end{array}$ & $\begin{array}{r}10.3 \\
9.3\end{array}$ & $\begin{array}{l}0.7 \\
7.0\end{array}$ & $\begin{array}{l}39.0 \\
22.5\end{array}$ & $\begin{array}{l}34.9 \\
37.2\end{array}$ & $\begin{array}{l}15.1 \\
24.0\end{array}$ & 0.002 \\
\hline
\end{tabular}

*Includes all milk consumers. Data have been adjusted to include the eight women who consumed more than one type of milk.

†Analysis by chi-square tests.

women, however, preferred modified milks to whole milk (35\% of 134 women). Around $27 \%$ of older women consumed skim milk, followed by reduced fat/higher calcium milk (21\%) and high calcium/skim milks (19\%). (These data include the eight women who consumed more than one type of milk.)

\section{Factors associated with milk choice}

Table 1 presents the relative importance to milk consumers of eating foods low in fat, cholesterol or energy, high in dietary fibre or calcium, or limiting their intake of added sugar and sugary foods. The importance of all these dietary attributes were significantly different between the two groups of women. Older women generally rated their importance higher than younger women. Foods low in fat, cholesterol and energy were rated as very or extremely important by $49 \%, 45 \%$ and
$36 \%$, respectively, of the younger group of women, and foods high in calcium as very or extremely important by half of the younger group. For the older group of women, foods low in fat, cholesterol or energy were rated as very or extremely important by $67 \%, 59 \%$ and $53 \%$, respectively, and foods high in calcium as very or extremely important by $57 \%$ of the older group. As shown in Table 2, eating foods low in fat was rated by more women as the most important issue than any other, with far more older aged women nominating this option compared with younger women. Limiting energy was a low priority for both groups, with cholesterol being more important to older women than calcium, and vice versa for the younger group. These results are consistent with the higher number of older women choosing non-whole milks in general and skim and low-fat milks in particular compared with the younger women.

Table 2 Relative importance to milk consumers of food attributes of fat, dietary fibre, cholesterol, calcium, energy and added sugar by age group and by type of milk consumed (per cent consumers)

\begin{tabular}{|c|c|c|c|c|c|c|}
\hline \multirow[b]{2}{*}{$\begin{array}{l}\text { Most important } \\
\text { food attribute }\end{array}$} & \multicolumn{2}{|c|}{ Age group* } & \multicolumn{4}{|c|}{ All women $†$} \\
\hline & $\begin{array}{c}\text { Younger } \\
\text { women } \\
(\%) \\
(n=135)\end{array}$ & $\begin{array}{c}\text { Older } \\
\text { women } \\
(\%) \\
(n=121)\end{array}$ & $\begin{array}{c}\text { Whole milk } \\
(\%) \\
(n=107)\end{array}$ & $\begin{array}{c}\text { Skim milk } \\
(\%) \\
(n=39)\end{array}$ & $\begin{array}{c}\text { Reduced fat/ } \\
\text { higher calcium } \\
(\%) \\
(n=52)\end{array}$ & $\begin{array}{c}\text { High calcium/ } \\
\text { skim } \\
(\%) \\
(n=37)\end{array}$ \\
\hline Low in fat & 34.8 & 54.5 & 39.3 & 61.5 & 50.0 & 35.1 \\
\hline High in fibre & 32.6 & 17.4 & 31.8 & 10.3 & 21.2 & 24.3 \\
\hline High in calcium & 11.1 & 8.3 & 9.3 & 7.7 & 7.7 & 18.9 \\
\hline Low in cholesterol & 7.4 & 10.7 & 4.7 & 12.8 & 7.7 & 18.9 \\
\hline Limited in added sugar & 7.4 & 8.3 & 10.3 & 5.1 & 7.7 & 0.0 \\
\hline Low in energy & 6.7 & 0.8 & 4.7 & 2.6 & 5.8 & 2.7 \\
\hline
\end{tabular}

* The two groups of women have ranked the importance of the food attributes differently $(P=0.002)$. Analysis by chi-square tests.

$\dagger$ Excludes the eight women who consumed more than one type of milk. Women who consumed the different milk types ranked the importance of the food attributes differently $(P=0.043)$. Analysis by chi-square tests. 
To test this interpretation, milk consumers, regardless of age, were grouped by the type of milk they consumed and their ranking of food attributes most important to health were reassessed. As shown in Table 2, 'eating foods low in fat' still ranked as the number one issue regardless of the type of milk consumed. However, a lower proportion of the women who consumed whole milk chose 'eating foods low in fat' (39\%) as the most important health issue than those consuming skim (62\%) or reduced fat/higher calcium milk (50\%). Eating foods high in fibre was the other key issue for whole milk consumers (32\%). Skim milk consumers ranked eating foods low in fat or cholesterol as their key dietary attributes. Calcium ranked fourth for this group. The reduced fat/higher calcium milk consumers had a pattern that sat between that of whole and skim milk consumers, eating foods low in fat ranked first and eating food low in cholesterol or high in calcium ranking equal third. Those who consumed the high calcium/skim milk formed four distinct groups. While eating foods low in fat was still the most important issue for the largest number of women (35\%) and eating foods high in dietary fibre ranked second (24\%), more women consuming this type of milk nominated high calcium or low cholesterol (19\% each) as their most important food attribute than any of the other groups of milk consumers.

The type of milk consumed also differed with employment $(P=0.012)$, living arrangements $(P=0.004)$ and reporting of certain health conditions: high blood pressure ( $P=0.02)$, being overweight $(P=0.012)$ and osteoporosis $(P=0.001)$. There were too few women (less than 24 women) reporting other health conditions (i.e. heart condition, growth or cancer, respiratory problems, being underweight, anaemia, diabetes) for statistical analysis against type of milk consumed. Whole milk was more likely to be consumed by women who worked (49\% full time, $46 \%$ part time), or who were carrying out 'home duties' (58\%) or who lived in households containing children (55\%). Fat-modified milks (particularly skim milk) were consumed by women who were retired, or on pensions (66\%) or living alone (65\%). Women who reported having high blood pressure ( 45 women) or being overweight (100 women) were more likely to be consuming fat-modified milks, particularly skim and reduced fat/higher calcium milks, respectively. Of the 35 women who reported having osteoporosis, seven consumed whole milk, 12 skim milk, six reduced fat/higher calcium milk and nine high calcium/skim milk. These differences were consistent with those demonstrated by age alone. Education or the taking of supplements was not associated with differences in the type of milk consumed.

\section{Milk choice and its impact on calcium intake}

As shown in Table 3, older women consumed more milk per day, more total calcium and more calcium from milk than younger women. With the sole exception of skim milk, older women consumed a greater quantity of milk regardless of the type of milk chosen. For the younger women, consumers of the milk with the high calcium content consumed the least milk, and those who chose the lowest fat milk (skim) consumed the greatest quantity of milk. For older women, however, those consuming whole milk consumed the lowest quantity, and those consuming the reduced fat/higher calcium milk consumed milk in the greatest quantities. The impact of the type of milk on mean calcium provided from this component of the diet is demonstrated, and combined with the generally higher

Table 3 Estimated quantity of milk and calcium consumed by milk consumers* and consumers of particular milk types (mean and SD)

\begin{tabular}{|c|c|c|c|c|c|}
\hline & \multirow[b]{2}{*}{ Milk consumers ${ }^{\star}$} & \multicolumn{4}{|c|}{ Milk type consumed } \\
\hline & & Whole fat & Skim & $\begin{array}{l}\text { Reduced fat/ } \\
\text { higher calcium }\end{array}$ & $\begin{array}{c}\text { High calcium/ } \\
\text { skim }\end{array}$ \\
\hline \multicolumn{6}{|l|}{ Sample size $(n)$} \\
\hline All women & 277 & 125 & 48 & 61 & 43 \\
\hline Younger women & 143 & 80 & 13 & 33 & 17 \\
\hline Older women & 134 & 45 & 35 & 28 & 26 \\
\hline \multicolumn{6}{|c|}{ Quantity consumed (ml) } \\
\hline All women & $353( \pm 267)$ & $322( \pm 257)$ & $391( \pm 288)$ & $390( \pm 273)$ & $349( \pm 263)$ \\
\hline Younger women & $318( \pm 238) \dagger \ddagger$ & $309( \pm 236)$ & $393( \pm 369)$ & $334( \pm 221) \ddagger$ & $276( \pm 147) \ddagger$ \\
\hline Older women & $390( \pm 291) \dagger \ddagger$ & $346( \pm 291)$ & $391( \pm 258)$ & $457( \pm 314) \ddagger$ & $397( \pm 310) \ddagger$ \\
\hline \multicolumn{6}{|c|}{ Calcium from milk (mg) } \\
\hline All women & $469( \pm 361)$ & $388( \pm 307)$ & $470( \pm 345)$ & $562( \pm 393)$ & $569( \pm 428)$ \\
\hline Younger women & $415( \pm 305) \neq \S$ & $371( \pm 283)$ & $471( \pm 443)$ & $471( \pm 319) \ddagger$ & $450( \pm 240) \ddagger$ \\
\hline Older women & $527( \pm 406) \ddagger \S$ & $420( \pm 346)$ & $469( \pm 309)$ & 657 (土453)‡ & $648( \pm 506) \ddagger$ \\
\hline \multicolumn{6}{|c|}{ Calcium intake $\left(\mathrm{mg} \mathrm{day}^{-1}\right)$} \\
\hline All women & $763( \pm 427)$ & $674( \pm 362)$ & $760( \pm 498)$ & $879( \pm 418)$ & $859( \pm 481)$ \\
\hline Younger women & $730( \pm 400) \ddagger$ & $671( \pm 359)$ & $774( \pm 738)$ & $827( \pm 355)$ & $781( \pm 283) \ddagger$ \\
\hline Older women & 799 (土453)‡ & $681( \pm 373)$ & $755( \pm 387)$ & $940( \pm 482)$ & $910( \pm 575) \ddagger$ \\
\hline
\end{tabular}

${ }^{*}$ For comparative purposes, only women who reported consuming one type of milk are included.

$\dagger$ There is a difference in the quantity of milk consumed by age alone for all milk consumers $(P=0.05)$. One-way analysis of variance test used.

$\ddagger$ Data were subject to transformation prior to statistical analyses.

$\S$ There is a difference in the calcium obtained from milk by age alone for all milk consumers $(P=0.022)$. One-way analysis of variance test used. 
quantity of milk consumed explains the higher mean calcium intake of the group of older aged women compared with that of younger women.

\section{Discussion}

The women in this study appear to have a similar mean calcium intake to that reported by 24-hour recall for women in the 1995 NNS, including those living in the capital cities only $^{10}$. ACT women aged 19 years and over were reported to have the highest mean calcium intake for all states and territories ( $\left.799.6 \mathrm{mg} \mathrm{day}^{-1}\right)^{10}$ and people in the ACT were more likely than those in other parts of Australia to be consuming milk and milk products on the day of the survey ${ }^{18}$. Further, our study and the NNS reported lower mean calcium intakes than those reported by women living in the states of Victoria in $1990^{16}$ and South Australia in $1993^{17}$. While the Victorian and South Australian studies used a semiquantitative food frequency instrument for assessing diets, differences in reference serve sizes of dairy products or in the range of foods included may account for the apparent discrepancies. Making comparisons of reported intakes of calcium in different studies is complicated by differences in research methods and in participant categorization used in reporting. While short, targeted FFQs such as the one in this study have limitations for measuring nutrient intake, these comparisons with other contemporary surveys suggest that the dietary information obtained is believable. Regardless of their methodological differences, all of these recent studies suggest that calcium intake has increased in Australia since the 1983 National Dietary Survey ${ }^{9}$.

The present study suggests that older women are consuming more calcium than younger women, the reverse of that reported in the 1983 National Dietary Survey $^{9}$ or the 1995 NNS $^{10}$. This may reflect the high education levels and household incomes in the $\mathrm{ACT}^{34}$, its affluent urban community and its low proportion of residents aged over 65 years $^{34}$. These factors and/or differences in consumption patterns related to the increasing availability and acceptability of milks with lower fat and higher calcium levels may also differ from other areas of Australia, particularly for older women. Public education programmes, marketing and advertising have given particular emphasis to the importance of dairy food consumption by children and older women. However, in spite of these potential influences, older women in this study had a mean calcium intake that was still 20\% less than the RDI of $1000 \mathrm{mg}$ for postmenopausal women ${ }^{3}$. The mean calcium intake for the younger group of women was also lower than the RDI of $800 \mathrm{mg}$ by around $10 \%$. While the method used for estimating calcium intake has limitations, the low estimates for calcium levels observed in this study suggest that some women from both age categories may be consuming suboptimal levels of calcium.
The findings of this study are consistent with previous national data. As those studies have shown, milk and milk products were the main source of calcium in the diet, with milk being the dominant contributor to calcium intake. In the food supply, milk and milk products provide $75 \%$ of the calcium available per capita, with milks alone contributing $50 \%{ }^{13}$. In diet surveys, the contribution to total calcium attributed to milk and milk products in total tends to be around 55-60\% ${ }^{9,10,16,17,35}$. Similarly, in this study, milk alone was the dominant dairy product consumed and thus the main source of dietary calcium, although the proportion from milk alone is higher than in other studies; 55-66\% compared with 32\% in the 1995 NNS. In part this is due to the FFQ reporting milk in total, regardless of its uses in cooking, etc., compared with 24-hour recall which reports foods in the form in which they are eaten. It is also related to the intent of the short FFQ to enable identification of major sources of calcium only, to provide an appropriate calcium level relative to a full dietary measure, and to provide for consistent and appropriate relative ranking of participants on the basis of this calcium measure. Regardless, the NNS data indicated that ACT adults (men and women combined) are the highest consumers of the key sources of calcium, milk, yoghurt and cheese in Australia. However, our study clearly shows that there were distinct differences in the type of milks consumed by the two groups of women. The majority of younger women chose whole-fat milks, whereas older women preferred fat-modified milks.

With the exception of consumers of skim milks, where the quantity consumed is the same in both groups, older women consume more milk than do younger women. The difference varies from 13\% more for whole milk consumers to $37 \%$ more reduced fat/higher calcium milk and $44 \%$ more high calcium/skim milks. These higher consumption levels of milk by older women result in higher calcium intakes compared with younger women. The effect of the type of modified milk consumed can be seen by comparing the calcium available to older women from milk for those who chose skim milk and those who chose the high calcium/skim milks. Both subgroups of women consume similar quantities of a skim milk (391 and $397 \mathrm{ml}$ ), and obtain similar, negligible amounts of fat from these milks. However, those older women consuming the high calcium form of skim milk $(397 \mathrm{ml})$ benefit from a $38 \%$ higher calcium intake than those women choosing the standard skim milk (i.e. 648 vs. $469 \mathrm{mg}$ calcium). Similarly, the benefits to calcium intake of consuming reduced fat/higher calcium milk rather than skim milk or whole milk are clearly demonstrated. Further, the results show that, with one exception, those women choosing the fat-modified milks consume higher quantities than those choosing whole milk. Conversely, younger women, consuming the type of milk that provides minimal fat with the highest calcium 
levels (high calcium/skim milk) consume the lowest quantities.

The Australian dietary guidelines have recommended an increased consumption of calcium, for women of all ages ${ }^{1,2,12}$. This has been accompanied by public health nutrition programmes, and marketing promoting milk consumption and the high calcium skim milks in particular. This study shows that the type of milk consumed has the larger impact on total calcium consumed, irrespective of age, followed by the quantity of milk consumed. While more younger women than older women chose the higher calcium milks, older women benefited from their higher intake of milk, as reflected in their higher calcium intakes. These benefits would be greater if more older women chose to consume the higher calcium milks. The generally higher quantities of milk consumed by older women may reflect differences in lifetime patterns of consumption of milk as suggested by Sandler and colleagues ${ }^{36}$ and past and current milk intakes have been shown to be associated with higher bone density ${ }^{36,37}$. Other studies have suggested that the attitudes affecting choice of milk type and intake include liking milk $^{38}$, attitudes to taste ${ }^{39}$, preferences of other household members ${ }^{39}$ and health-related concerns ${ }^{38}$ (e.g. calories, cholesterol, gastrointestinal disturbances). While the higher proportion of older women consuming fatmodified milks may be partly explained by their higher prevalence of cardiovascular risk factors such as being overweight, and high blood pressure, it does not explain the type of fat-modified milk being consumed. Despite the high level of educational attainment in our study groups, the continuing choice of lower calcium milks may suggest an inadequate knowledge of the level of calcium (and fat) in the different milks and/or about how much calcium should be consumed to meet current recommendations. This study suggests that older women have shifted preferences to lower fat milks and are favouring skim milk. This choice appears to reflect the ranking of 'eating low-fat foods' as the most important food attribute for over half of the older women. However, as indicated above, there may be other reasons why these women were not consuming the reduced fat/higher calcium milks or consuming higher quantities of milk that were not assessed in this study. One explanation for this shift may lie in the apparent emphasis towards lowering fat, particularly animal fat, in the public health nutrition messages.

These results confirm that concern about the fat content of foods is the major factor influencing the choice of milk for those consuming skim milk or reduced fat/higher calcium milks. For those consuming whole milk, fat is an issue for many but is not as great a concern (by itself, or in concert with cholesterol or energy) as it is for other groups. For those choosing the high calcium/skim milks, eating food low in fat is the major issue, but eating foods low in cholesterol and/or high in calcium are also important determinants of milk choice.

\section{Conclusions}

Lifetime calcium intake is important for health outcomes for women of all ages. Although the milk and calcium intakes of older women are higher compared with those of younger women, concern about fat intake is prejudicing the type of milk chosen, and thus the maximizing of calcium intakes. Current education messages are not addressing the interpretation and priorities that women must make in response to the separate messages 'eat less animal fat' and 'consume a diet high in calcium'. For younger women, the lifetime importance of improving calcium intake is greater, but their milk and calcium intakes are lower than those of older women. To optimize their effectiveness, public health strategies intended to increase calcium intake in women need to address agerelated differences in quantity and type of milk consumed, including the food attribute conflicts that influence these consumption patterns.

\section{Acknowledgements}

These data were collected by Ms Lilian Onyango in collaboration with the authors as part of her Masters of Applied Science. Ms Onyango is now deceased. Analysis of these data was supported by ACT Healthpact (the Australian Capital Territory's health promotion authority). Dr Crawford was supported by an NHMRC Public Health Research Fellowship and is currently supported by a Heart Foundation Nutrition Research Fellowship.

\section{References}

1 National Health and Medical Research Council. Dietary Guidelines for Australians. Canberra: Australian Government Publishing Service, 1992.

2 National Health and Medical Research Council. Dietary Guidelines for Children and Adolescents. Canberra: Australian Government Publishing Service, 1994.

3 National Health and Medical Research Council Recommended Dietary Intakes for Use in Australia. Canberra: Australian Government Publishing Service, 1991.

4 Nordin C. Calcium. In: Truswell AST et al., eds. Recommended Nutrient Intakes: Australian Papers. Sydney: Australian Professional Publishers, 1990; 201-19.

5 National Institutes of Health. Optimal Calcium Intake. NIH Consensus Statement online, 6-8 June 1994, 12(4): 1-13 1994.

6 Bronner F. Calcium and osteoporosis. Am. J. Clin. Nutr. 1994; 60: 831-6.

7 MacKerras D. Calcium intake and osteoporosis. Aust.J. Nutr. Diet. 1995; 52 (Suppl.): S3-25.

8 English R, Cashel K, Lewis J, Waters A, Bennett S. National Dietary Survey of Schoolchildren Aged 10-15 years. No. 2. Nutrient Intakes. Canberra: Australian Government Publishing Service, 1989.

9 English R, Cashel K, Bennett S, Berzins J, Waters A, Magnus P. National Dietary Survey of Adults: 1983. No. 2. Nutrient Intakes. Canberra: Australian Government Publishing Service, 1987.

10 Australian Bureau of Statistics (ABS). National Nutrition Survey. Nutrient Intakes and Physical Measurements. 
Australia 1995. Catalogue No. 4805.0. Canberra: ABS, 1998.

11 Seeman E. In: National Health and Medical Council, ed. Dietary Guidelines for Australians. Canberra: Australian Government Publishing Service, 1992; 95-104.

12 Kerr D. Include foods high in calcium. In: National Health and Medical Research Council, ed. Dietary Guidelines for Older Australians. Canberra: AusInfo, 1999; 121-31.

13 Australian Bureau of Statistics (ABS). Apparent Consumption of Foodstuffs and Nutrients, 1993-1994. Canberra: ABS, 1997.

14 English R, Cashel K, Lewis J, Bennett S, Berzins J, Penm R. National Dietary Survey of Schoolchildren (aged 10-15 years): 1985. No. 1. Foods Consumed. Canberra: Australian Government Publishing Service, 1988.

15 Cashel K, English R, Bennett S, Berzins J, Brown G, Magnus P. National Dietary Survey of Adults. No. 1. Foods Consumed. Canberra: Australian Government Printing Service, 1986.

16 Baghurst K, Record S, Syrette J, et al. What are Australian's Eating. Results from the 1985 and 1990 Victorian Nutrition Surveys. Adelaide: CSIRO/Deakin University Food and Nutrition Program, 1993.

17 Baghurst K, Powis G, Record S, Baghurst P, Court M, Thompson G. Nutrition in South Australia from 1988 to 1993. Adelaide: CSIRO/Foundation SA, 1994.

18 Australian Bureau of Statistics (ABS). National Nutrition Survey. Foods Eaten. Australia 1995. Catalogue No. 4805.0. Canberra: ABS, 1999

19 Australian Bureau of Statistics (ABS). Apparent Consumption of Foodstuffs and Nutrients, 1988-89. Canberra: ABS, 1992.

20 Nowak M, Speare R. Gender differences in food-related concerns, beliefs and behaviours in North Queensland adolescents. J. Paediatr. Child Health 1996; 32: 424-7.

21 Worsley A. Australian's dietary and nutrition concerns. In: Truswell AST, Whalqvist M, eds. Food Habits in Australia. Melbourne: Rene Gordon, 1988; 122-45.

22 Crawford D, Baghurst K. Diet and health: a national survey of beliefs, behaviours and barriers to change in the community. Aust. J. Nutr. Diet. 1990; 47(4): 97-104.

23 Crawford D, Baghurst K. Nutrition information in Australia the public's view. Aust. J. Nutr. Diet. 1991; 48(2): 40-4.

24 Hughes R, Lund-Adams M, Heywood P. Reported dietary change amongst a group of Brisbane residents. Aust. J. Nutr. Diet. 1996; 53(1): 20-4.

25 Schwartz N. What do consumers really think about dietary fat? J. Am. Diet. Assoc. 1997; 7(Suppl.): S73-5.

26 Australian Dairy Corporation (ADC). 1997 Dairy Compendium. Melbourne: ADC, 1997.

27 Australian Capital Territory Milk Marketing Authority. Canberra Milk. Annual Report 1995/96. Canberra: ACT Government Printer, 1996.

28 Luoto R, Kaprio J, Uutela A. Age at natural menopause and sociodemographic status in Finland. Am.J. Epidemiol. 1994; 139(1): 64-76.

29 Leidy L. Timing of menopause in relation to body size and weight change. Hum. Biol. 1996; 68(6): 967-82.

30 Angus AM, Sambrook PN, Pocock NA, Eisman JA. A simple method for assessing calcium intake in caucasian women. J. Am. Diet. Assoc. 1989; 89(2): 209-14.

31 Cashel K, English R, Lewis R. Composition of Foods, Australia. Canberra: Australian Government Printing Service, 1989.

32 English R, Lewis J, Cashel K. Composition of Foods, Australia. Vol. 2. Cereals. Canberra: Australian Government Printing Service, 1991.

33 English R, Lewis J. Composition of Foods, Australia. Vol. 3. Dairy Foods. Canberra: Australian Government Printing Service, 1990.

34 McLennan W. Australian Social Trends 1996. ABS Catalogue No. 4102.0. Canberra: Australian Bureau of Statistics, 1996

35 Baghurst K, Record S, Syrette J, Powis G. Does 5 years Make a Difference? Results from the CSIRO Australian Food and Nutrition Surveys 1988 and 1993. Adelaide: CSIRO, 1996.

36 Sandler RB, Siemenda CW, LaPorte RE, et al. Postmenopausal bone density and milk consumption in childhood and adolescence. Am. J. Clin. Nutr. 1985; 42: 270-4.

37 Teegarden D, Lyle R, Proulx W, Johnston C, Weaver C. Previous milk consumption is associated with greater bone density in young women. Am. J. Clin. Nutr. 1999; 69: 1014-17.

38 Chapman K, Chan M, Clark C. Factors influencing dairy milk intake in women. J. Am. Coll. Nutr. 1995; 14(4): 336-40.

39 Brewer J, Blake A, Rankin S, Douglass L. Theory of reasoned action predicts milk consumption in women. J. Am. Diet. Assoc. 1999; 99: 39-44. 